By: Jane E. Myers

Myers, J. E. (2003). Coping with caregiving stress: A wellness-oriented, strengths-based approach for family counselors. The Family Journal, 11, 1-9.

Made available courtesy of Sage Publications: http://www.sagepub.com/home.nav

*** Note: Figures may be missing from this format of the document

\begin{abstract}
:
Caregiving has become a normative family stress that typically extends over multiple years. Traditional conceptualizations of caregiving in terms of burden and stress lead to interventions based in a medical model of care. Wellness is presented as an alternative model with the potential for empowering caregivers and helping them develop healthier lifestyles. A case example is presented to demonstrate how marriage and family counselors can use this approach to enhance wellness in caregivers and their families.

Keywords: wellness; strengths-based; caregiving; caregiving stress; caregiver burden
\end{abstract}

\title{
Article:
}

Tennstedt (1999) summarized existing research to document that almost one fourth of Americans currently experience a functional disability or require long-term care; further, the numbers of older Americans (i.e., those aged 60 and older) in this group will increase by $90 \%$ over the next half century. The majority of care for these individuals is provided by family and friends, with recent estimates suggesting that more than 22 million households, or 1 in 4 households nationally, include informal care providers (National Alliance for Caregiving and the American Association of Retired Persons, 1997). Caregiving can extend over a short period of time or, more typically, over extended years, and has become a normative "life event challenge" (Cavanaugh, 1998, p.131).

This challenge is singularly complex and multifaceted, is primarily explained in terms of stress, burden, and negative physical and mental health outcomes (e.g., Gallagher-Thompson, Coon, Rivera, Powers, \& Zeiss, 1998; Haug, Ford, Stange, Noelker, \& Gaines, 1999; Light, Niederehe, \& Lebowitz, 1994; Pearlin, Mullan, Semple, \& Skaff, 1990; Vitalioano, Schulz, Kiecolt-Glaser, \& Grant, 1997), and has become among the most frequently researched topics in social, psychological, and behavioral sciences. For example, a PsychINFO search using the keywords caregiving and caregiver burden resulted in 4,345 articles published over the past 10 years. Given the multidimensional nature of caregiving, the challenge to caregivers, consistent with the normative experience of aging, is to maintain a sense of personal wellness in the face of significant life challenges (Waters, 1995). Interestingly, the keywords caregiving and mental health resulted in only 347 PsychINFO articles in the past decade and caregivers and wellness only 11.

In this article, the consequences of caregiving and effects on physical and mental health are briefly examined. Models of stress and coping that have been proposed to explain the caregiving experience are discussed, followed by a brief review of mental health intervention programs based on research related to aspects of these models. The need for strength-based approaches to helping caregiving families is emphasized, and wellness is introduced as an example of a positive, holistic perspective for coping with caregiving challenges. The Wheel of Wellness model is presented and described as a basis for assessment and intervention with caregivers, and implications for family counseling and research are explored.

\section{CONSEQUENCES OF CAREGIVING}

Pearlin et al. (1990) distinguished between caring, "the affective component of one's commitment to the welfare of another," and "caregiving ... the behavioral expression of this commitment" (p. 583). They further note that, under the demands of constant care, caregiving expands to encompass the entirety of the caregiver- 
care recipient relationship. Financial, health, and emotional costs to caregivers have been well documented (Pearlin, 1994): Caregivers find it necessary both to relinquish outside employment and to increase expenditures for services, and they experience declines in physical as well as mental health.

Vitaliano et al. (1997) reported that caregivers experience poorer immune system functioning, poorer response to vaccines, and greater incidences of respiratory tract infections. Caregivers report physical stress and fatigue, exhaustion, a variety of medical conditions, and increased use of prescription medications (Haug et al. , 1999). They experience more chronic illness, provide self-ratings of health as poor, and may use health care services more often than do noncaregivers, though the latter findings are somewhat equivocal (Schulz \& Williamson, 1994). Schultz and Beach (1999) reported that caregiving is a risk factor for mortality, with persons providing care experiencing a $63 \%$ greater risk of death than a control group of noncaregivers.

The mental health consequences of caregiving have been linked to burden, the consequence of having to place the needs of care recipients before the needs of the caregiver (Baronet, 1999). A distinction is made between objective burden, including the negative effects on the household due to caregiving, and subjective burden, or personal appraisals of the caregiving situation and its consequences for the caregiver (Hoenig \& Hamilton, 1966). Objective burden has been found to be greatest in relation to assistance with activities of daily living, or personal care, whereas subjective burden has been found to be greatest with supervision activities (Baronet, 1999) and is most acute and sustained when dementia is present (Connell, Janevic, \& Gallant, 2001). Rabins (1998) noted that Alzheimer's care providers experience rates of emotional morbidity three times greater than do their same-aged noncaregiving age peers. The negative consequences of caregiving on mental health of the caregiver include increased distress, depression, demoralization, and anxiety, and psychiatric symptomatology such as insomnia, headaches, and excessive irritability (Schulz \& Williamson, 1994; Yee \& Schulz, 2000).

Comorbidity of physical and mental problems is the rule rather than the exception (Schulz \& Williamson, 1994). Not surprisingly, anxiety surrounding both the possibility and the reality of caregiving affects families before, during, and after the end of caregiving experiences (Schulz, Newsom, Fleissner, DeCamp, \& Nieboer, 1997). Understanding and alleviating the negative effects of caregiving requires attention to both physical and mental challenges, to antecedents as well as consequences of the caregiving role, and to factors that can mediate and/or moderate these consequences. Moreover, successful interventions require consideration of the extended impact of caregiving on all members of the family system, not just the front-line care provider (Knight \& McCallum, 1998; Zarit, Johansson, \& Jarrott, 1998).

\section{MODELS OF STRESS AND COPING}

Caregiving can have positive as well as negative effects, though negative effects are by far the best documented. Models purporting to explain both the positive and negative outcomes of caregiving experiences are primarily based in literature on stress and coping. Two comprehensive models that provide a strong foundation for both understanding and intervention are those developed by Schulz and Salthouse (1999) and Pearlin and his colleagues (1990).

\section{Schulz and Salthouse's General Model of the Stress-Health Process}

Schulz and Salthouse (1999) described a sequential, cyclical model in which stressful situations begin when functional limitations of the care recipient and problem behaviors create a need for caregiving. The potential caregiver must appraise the situation and decide if she (usually) or he can deal with the problems. A positive or benign appraisal leads to positive emotional responses and a sense of well-being. Alternately, an appraisal of the situation as stressful leads to negative emotional reactions (e.g., anxiety, depression); these reactions may interact with care recipient behaviors to create an escalation of negative outcomes. Caregiver health and mental health are affected, with concomitant increased risk for physical and emotional problems. Biegel and Schulz (1999) noted the existence of possible feedback loops, while also stating that "although the model is primarily unidirectional, we recognize that dealing with stressors is a complex, dynamic process in which responses at one stage ... may subsequently feed back to earlier stages" (p. 346). 
Pearlin et al. 's (1990) Conceptual Model of Caregiving Stress

Pearlin et al. (1990) presented a conceptual model of caregiving stress, specific to Alzheimer's caregivers but generally applicable to all caregiving situations, which depicts four domains of the stress process. The background and context of the stress include factors such as family and network composition, caregiving history, and socioeconomic status. Primary stressors include both objective and subjective indicators (i.e., objective burden and subjective burden). Secondary role strains include factors such as family conflict, economic difficulties, and constriction of social interactions. Secondary intrapsychic strains are described in terms of "global and overarching elements of the self" (p. 589), including self-esteem and mastery, and situational elements, such as role captivity and sense of competence. The outcomes of this process include the negative mental health consequences described above. The stress process is cyclical and interactive, and specific elements and outcomes are mediated by coping resources and social support.

\section{Research on Caregiver Stress, Coping, and Mental Health}

Pearlin et al. (1990) attempted the monumental task of studying all components of their caregiving stress model simultaneously and concluded,

It is useful to think of caregiver stress not as an event or as a unitary phenomenon. It is, instead, a mix of circumstances, experiences, responses, and resources that vary considerably among caregivers and that, consequently, vary in their impact on caregivers' health and behavior. The mix is not stable; a change in one of its components can result in a change in the others." (p. 591)

Gallagher-Thompson and Powers (1997) examined the relationship between primary stressors and mental health in a sample of 91 caregivers and found that each primary stressor was significantly related to caregiver depression. They emphasized the importance of the subjective evaluation of stressors as well as the mediating role of self-efficacy, and underscored the need for examining the effects of both ethnicity and religiosity on caregiver well-being.

Pearlin et al. (1990) found that long-term caregiving depletes social support resources and reduces perceptions of control. Numerous studies support the reduction in social support that occurs over time concomitant with caregiving roles, and this loss is directly related to declines in mental and emotional health (Haug et al. , 1999) for Black as well as White caregivers (Haley et al. , 1995). On the other hand, it appears that caregiving stress can be mediated by physical, psychological, and environmental resources of caregivers (Baronet, 1999). It is important to note that social support has emerged as the greatest moderator of the effects of caregiver stress (Logsdon \& Robinson, 2000; Vrabec, 1997). Other moderators of stress include positive reappraisal, goaldirected, problem-focused coping, spiritual beliefs, and reframing ordinary events with positive meaning (Folkman, 1997).

\section{INTERVENTION PROGRAM FOR CAREGIVER MENTAL HEALTH}

The relationships between stress and coping, as postulated in models and supported by the results of numerous empirical studies, have resulted in a variety of intervention programs designed to reduce caregiver stress and increase their wellbeing. Three widely used types of intervention include respite care, support groups and counseling, and family interventions.

Respite care provides a "time out" for caregivers by providing an alternate means of assistance to care recipients for a short period of time, lasting from a few hours to a few days. McNally, Ben-Shlomo, and Newman (1999) conducted a review of 29 studies of respite care and concluded that "respite intervention has neither a consistent or enduring beneficial effect on carers' well-being" (p. 1). These authors underscored the need for a more "carer centered" (p. 1) approach to the respite care experience.

The strong relationship between social support and caregiver subjective burden has given rise to an emphasis on support groups for caregivers as a means of reducing perceived stress. Research on the efficacy of support 
groups is equivocal. For example, using a delayed-treatment control group design, Schwiebert and Myers (1994) found no differences in caregiver burden as a result of support group participation; however, there was a significant increase in coping resource effectiveness for 51 caregivers who participated in a structured group experience. Roberts et al. (2000) conducted a systematic review of literature on services and models of care for dementia caregivers, and did not even include support groups, based on Lavoie's (1995) conclusion that support groups simply do not work. In contrast, Roberts et al. (2000) found that individual, supportive counseling in Canada was effective in reducing the number of nursing home placements, particularly at the early stages of dementia, and was instrumental in increasing psychosocial adjustment to care recipient's illnesses among caregivers with poor coping skills. Rabins (1998) also noted the importance of early intervention among high-risk (i.e., dementia) caregivers, suggesting that emotional and social care early in the disease process may prevent the development of physical as well as emotional problems.

The processes of aging and disability are gradual; hence, the onset of caregiving responsibilities in families is slow and almost insidious, with spouses emerging as primary caregivers (Zarit, Birkel, \& Malone-Beach, 1989). Spouse caregivers are especially vulnerable as they "provide the most comprehensive care ..., maintain the caregiving role for longer periods, care for the most impaired individuals, and spend the most hours per week on caregiving tasks" (Connell et al. , 2001, p. 180). Spouses also have higher levels of depression, lower levels of life satisfaction, and lower participation in social activities than do other caregivers in the family (Connell et al. , 2001).

Gallagher-Thompson et al. (1998) reported that $75 \%$ of caregivers feel that caregiving makes them feel useful; possible positive feelings include self-worth, confidence, and companionship. However, anger, frustration, and other symptoms of caregiver distress are predominant emotions. Because caregiving occurs in family settings, the impact of these emotions is felt first and foremost in the family (Muscroft \& Bowl, 2000). Family-based interventions are needed to help caregivers cope effectively with stress and the many challenges of role definition and redefinition when the physical and/or mental well-being of loved ones declines (Cavanaugh, 1998; Knight \& McCallum, 1998; Zarit et al., 1998).

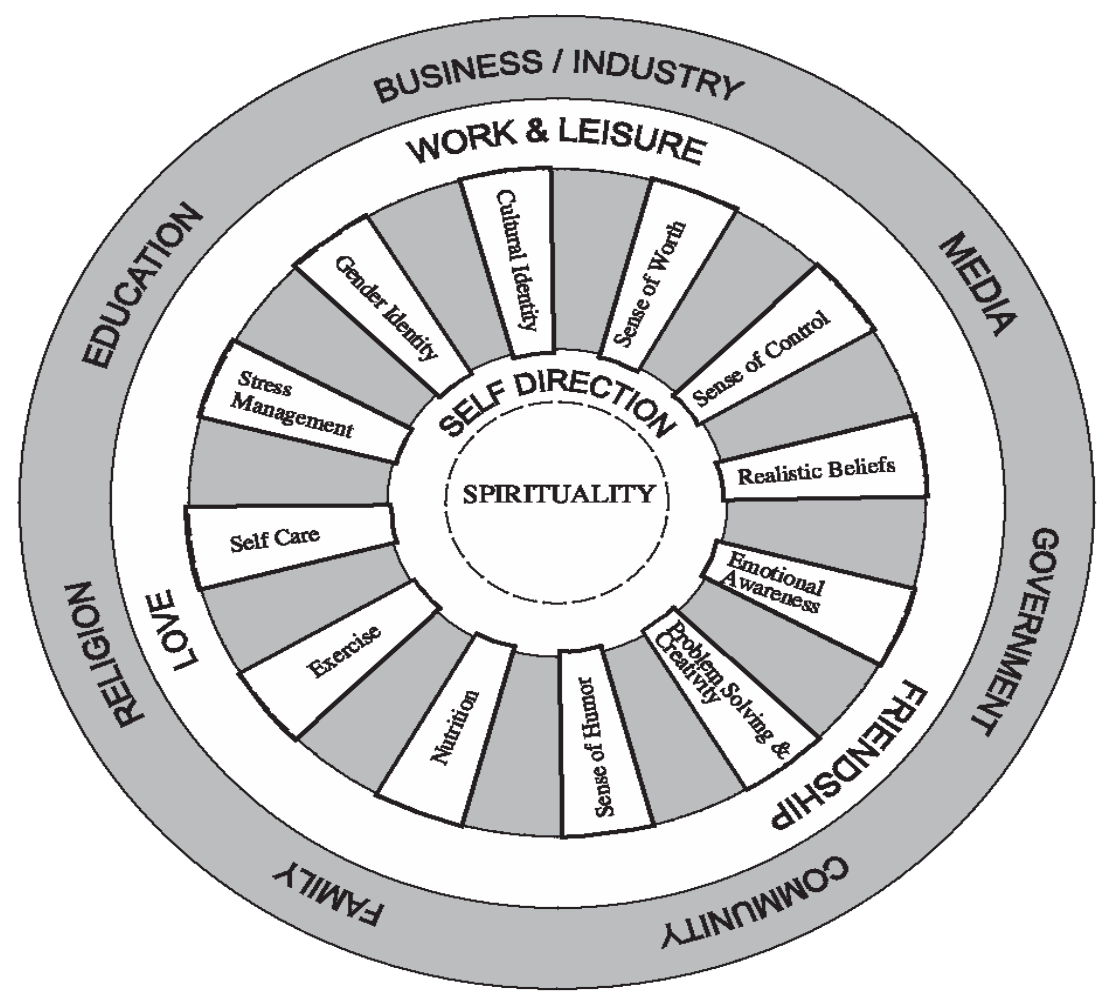




\section{WELLNESS-ORIENTED, FAMILY- BASED INTERVENTIONS FOR CAREGIVERS}

As noted earlier, most studies of caregiver intervention focus on the negative aspects of the caregiving role and treatment once problems have escalated. In contrast, wellness-oriented approaches provide a focus on strengths as well as prevention of problems once caregiving roles are assumed. In this section, wellness is introduced and defined, and a model of wellness originating in counseling theory is described. Use of the model in assessment and intervention with family caregivers is explored, and a case example designed to promote caregiver wellness is presented.

\section{Wellness as a Foundation for Conceptualizing Caregiver Burden}

Wellness is not a new concept; in fact, the customs of the ancient Greeks and reports of health practices throughout the centuries are suggestive of a concern for wellness (Witmer, 1996). The World Health Organization as early as 1947 defined health as "physical, mental, and social well-being, not merely the absence of disease" (World Health Organization, 1958, p. 1) and later provided a definition of optimal health as "a state of complete physical, mental, and social well-being and not merely the absence of disease or infirmity" (World Health Organization, 1964, p. 1). More recently, Archer, Probert, and Gage (1987) concluded that wellness may be defined as "the process and state of a quest for maximum human functioning that involves the body, mind, and spirit" (p. 311). Dunn (1961), who is widely credited as being the father of the modern wellness movement, defined wellness as "an integrated method of functioning which is oriented toward maximizing the potential of which the individual is capable" (p. 4). He also suggested that counselors were in a unique position to help individuals achieve high-level wellness (Dunn, 1977).

Viewing caregiving from a wellness perspective requires that counselors examine the strengths of individuals and develop strategies for enhancing resilience and personal empowerment (Cadell, Karabanow, \& Sanchez, 2001). Recent research suggests that caregiver wellness can be enhanced through training in social problem solving (Kurylo, Elliott, \& Shewchuk, 2001), help with effective decision making (Lewis et al. , 2000), encouragement of leisure pursuits (Bedini \& Phoenix, 1999; Hawkins \& Kultgen, 1990), social support (Rogers, 1999), and preventive health practices (Matthews, 1998). Each of these methods is integral to holistic wellness.

\section{Models of Wellness for Counselors}

Counselors seeking a basis for wellness interventions have a variety of theoretical models from which to choose. For example, Hettler (1984), a public health physician and medical educator, proposed a hexagon model which specifies six dimensions of healthy functioning, including physical, emotional, social, intellectual, occupational, and spiritual. Hinds (1983), also a university-based health educator, developed a model of lifestyle coping to help individuals deal with stress management and health promotion. The difficulty with these models for counseling-oriented professions is that each has a firm basis in health care rather than psychological development, with the latter receiving far less emphasis in health promotion and disease prevention programs based on these theories (Erfurt, Foote, \& Heirich,1991; Roberts \& Harris, 1989). In contrast, the Wheel of Wellness model (Sweeney \& Witmer, 1991; Witmer \& Sweeney, 1992) is based in counseling theory and provides a foundation for designing counseling interventions for individuals and families (Myers, Sweeney, \& Witmer, 2000).

The Wheel of Wellness model was developed following cross-disciplinary research linking healthy behaviors to life satisfaction, longevity, and quality of life (Sweeney \& Witmer, 1991). This model is grounded in Adlerian individual psychology, an approach to helping that emphasizes the importance of holism in understanding the individual (Adler, 1927/1954). Adler (as cited in Ansbacher \& Ansbacher, 1956) noted that "it is always necessary to look for ... reciprocal actions of the mind on the body, for both of them are parts of the whole with which we should be concerned" (p. 255). Jung (1958) also observed that the human psyche actively moves toward a state of integration, based on an instinctual drive toward health and wholeness. Maslow (1954/1970), in studying characteristics of healthy persons, concluded that a striving toward self-actualization, growth, and excellence is a universal human tendency and overarching life purpose. 
The Wheel of Wellness model proposes 5 life tasks, depicted in a wheel (see Figure 1), which are interrelated and interconnected: spirituality, work and leisure, friendship, love, and self-direction. The life task of selfdirection is further subdivided into the 12 tasks of (a) sense of worth; (b) sense of control; (c) realistic beliefs; (d) emotional responsiveness and management; (e) intellectual stimulation, problem solving, and creativity; (f) sense of humor, (g) exercise, (h) nutrition, (i) self-care, (j) gender identity, (k) cultural identity, and (l) stress management. These life tasks interact dynamically with a variety of life forces, including but not limited to one's family, community, religion, education, government, media, and business/industry. Global events, whether of natural (e.g., floods, famines) or human (e.g., wars) origin also can have an impact on the life forces and life tasks depicted in the model.

Research using the wheel model suggests its utility for conceptualizing individuals from a wellness perspective. For example, Hermon and Hazler (1999) demonstrated an empirical link between the five life tasks and perceptions of happiness and psychological well being. Dew (2000) found wellness to be positively related to self-disclosure and negatively related to internalized homophobia in adult gay males. Myers, Madathil, and Tingle (in press) examined cross-cultural differences in marriage satisfaction and wellness among married couples living in the United States in marriages of choice and those in India living in arranged marriages; they found no differences in marriage satisfaction or love but significant differences in cultural identity, nutrition, and other components of the wheel model. These studies demonstrate the value of a wellness model in examining factors of importance to counselors and raise the question of how such a model could be used to help family caregivers.

\section{USING A WELLNESS MODEL WITH FAMILY CAREGIVERS}

Myers et al. (2000) suggest a four-phase approach for using the Wheel of Wellness in counseling. These four phases include introducing and explaining the wheel model, assessing the wellness of the client or family, developing appropriate interventions to enhance wellness, and evaluating the effectiveness of the interventions. A feedback loop is part of the model, so that the results of the evaluation can be used to structure additional interventions as needed. Further, assessment can be informal using a clinical interview format or formal using an instrument such as the Wellness Evaluation of Lifestyle (Myers, Sweeney, \& Witmer, 1998) that was developed based on the Wheel of Wellness model. An example of the application of the four phases with a family caregiver is presented to demonstrate the wellness paradigm for assessment and intervention.

\section{Description of the Client}

B. K. is a 60-year-old, African American female. She has been married for 33 years and has two children, a 33year-old daughter and a 30-year-old son. B. K.'s husband works for a local manufacturing company. Her son works as an automobile salesman, and she has little contact with him. Her daughter has a history of substance abuse and was living in an inpatient rehabilitation program when B. K. was referred for counseling.

B. K. began caregiving 8 years earlier when her mother was diagnosed with Alzheimer's disease. At that time, she quit her job working in a bakery and has devoted full time to her caregiving role. She also cares for her 59year-old sister, who has diabetes mellitus and multiple additional disabling conditions and lives in her home. She is primary caregiver as well for her daughter's 14-year-old son. B. K., her sister, husband, and grandson live in a small home in a low-income neighborhood. Their combined family income places them at the federal poverty level.

B. K. has been under medical treatment for depression and anxiety but takes no prescription medications. Her physical health is generally good, in that she is not ill; however, she reports having low energy most of the time.

\section{Phase 1: Introduction of the Model}

B. K. was provided a copy of the Wheel of Wellness model and each component of the model was explained. She was given the opportunity to ask questions and was asked to repeat several of the explanations to determine her personal understanding of the wellness concepts. 
B. K. was asked several general scaling questions to determine her overall perceptions of her own wellness (e.g., On a scale of 1 to 10, how well do you think you are? On a scale of 1 to 10, how satisfied are you with your life right now?). In addition, B. K. completed the Wellness Evaluation of Lifestyle, and her scores were provided in a profile compared to norms for an over-50 population. As shown in Figure 2, B. K. scored below the norm group on 16 of 19 scales, notably the major life tasks of work, leisure, friendship, and love, as well as the self-direction subtasks of sense of control, realistic beliefs, sense of humor, nutrition, and exercise. She scored highest, and higher than the norm group, on spirituality and self-care. She explained her scores in terms of her strong spiritual beliefs that "help me get through all this."

\section{Phase 3: Designing and Implementing Wellness Interventions}

B. K.'s wellness profile reflects compromised wellness in most areas with major strengths being a lack of negative self-soothing behaviors combined with positive health habits, such as not smoking or using illegal drugs, and strong faith beliefs that also result in strong social support through her faith community. Myers et al. (2000) recommend designing interventions to affect a limited number of wellness components, perhaps only one or two, in order to avoid overwhelming the client and also to increase the potential for creating success experiences and overall positive outcomes. They note the interactive nature of wellness components, such that change in any one area will contribute to or cause changes in other areas as well.

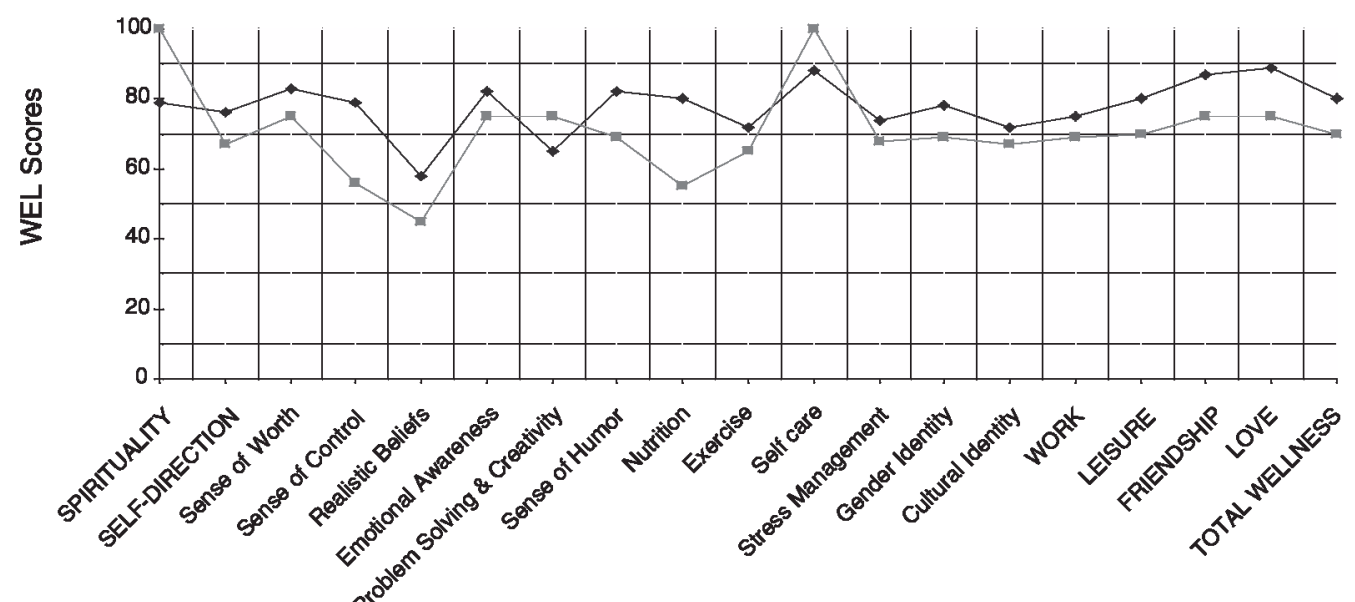

WEL Scales

FIGURE 2: Sample Caregiver Wellness Profile

A variety of interventions could be designed for B. K. that would potentially affect her overall wellness.

Following a review of her scores, she chose two areas for her initial treatment plan, noting that these areas were interrelated and that perhaps she could improve not only her own wellness but the wellness of those around her if she could become more well herself. These two areas were sense of humor and leisure, both of which she suggested were low scores because she had become a very serious person since taking on multiple caregiving roles, and she wanted to learn to laugh again. She also felt that she had no time for herself and nothing that could be defined as free or leisure time. By engaging others in her humor and leisure activities, it is reasonable to assume that her family relationships as well as the health and wellness of other family members would improve also. Additional benefits that would be expected as a result of improving her leisure and humor would be that her friendship with her sister and love relationships within her family would improve as she became more able to relax and enjoy life. 
According to the Wheel of Wellness, a healthy sense of humor includes the ability to laugh appropriately at oneself, the ability to laugh appropriately at others, having the capacity to see contradictions and predicaments of life in an objective manner such that one can gain new perspectives, the ability to use humor to cope with one's own difficulties, and the ability to enjoy the inconsistencies and idiosyncrasies of life. Leisure, those activities done in one's free time, is also defined as when a person experiences satisfaction with one's leisure activities, understands and appreciates the importance of leisure, has positive feelings associated with leisure, has at least one activity in which "I lose myself and time stands still," has the ability to approach tasks from a playful point of view, and has the ability to put work aside for leisure without feeling guilty. Given these definitions, it is easy to imagine the possibility of developing a wellness plan for leisure that incorporates elements of humor and vice versa.

B. K. indicated that she had no free time and no time for leisure due to her caretaking roles. She had no hobbies, nor did those with whom she lived. When they were home together, which was most of the time, the television was on and they sat in the living room and did not talk to one another. The family owned a VCR but made little use of it.

Attempts to get B. K. to develop a list of activities she might enjoy doing in her free time were met with resistance. She was convinced that she could not leave her family alone in order to participate in respite care, counseling, or anything she might do for herself. An interesting response resulted when the counselor reframed leisure as something she might do with others in the family in spite of, or in consideration of, their physical and mental challenges, and when humor was reframed as something the family might share (i.e., fun times) rather than just something B. K. would work on alone. She responded positively to the suggestion that the family could watch funny movies together, with the caveat that at least 15 minutes after each movie would be spent with each person's sharing their favorite scenes. B. K.'s spiritual beliefs did not preclude watching movies, and she knew of friends at her church who had collections of movies on videotape. She agreed to contact her friends by phone or in person after services on Sunday, explain that she wanted to watch some funny videos with her family, and ask if she could borrow one or two from them.

B. K. agreed to do what she considered a "very small thing' in reaching out to others to borrow videos. Following Prochaska, Norcross, and DiClemente's (1994) suggestions to "go public" with change efforts and ask for help from others to increase the chances of success, B. K. involved her family in her plan. Everyone agreed to watch funny movies with her and spend time discussing them. A minimum of two movies per week was planned.

\section{Phase 4: Evaluation and Follow-Up}

B. K.'s wellness plan was very brief and almost deceptively simple, yet it was designed to be simple both to increase the chances of success and to give her an experience of control over her environment and the circumstances of her life. As often happens with wellness behaviors, watching videos became an empowering stimulus, such that B. K. and her family enjoyed the activity and reinforced one another for continuing. Not only did they laugh, with concomitant physical and emotional benefits (Erdman, 1991), they also increased their sense of physical and emotional well-being through leisure (Zimmer \& Lin, 1996), which also positively affects self-esteem (Reitzes, Mutra, \& Verrill, 1995) and perceived wellness (Ragheb, 1993). As the family learned to laugh and talk together, it became easier to discuss more difficult issues related to caregiving and family patterns of interaction and coping.

\section{CONCLUSION}

Marriage and family counselors are uniquely positioned to offer interventions to individuals and families to facilitate coping with caregiver stress. Based on a philosophy of holism and an orientation toward optimal wellness, interventions can be structured that emphasize assets rather than limitations, and that treat caregiver burden through a focus on individual and family strengths rather than mental and physical pathology. Further 
research is needed using wellness interventions with family caregivers to provide models and strategies for helping caregiving families cope with stress and enhance the wellness of all members of the family.

\section{REFERENCES}

Adler, A. (1954). Understanding human nature (W. B. Wolf, Trans.). New York: Fawcett Premier. (Original work published 1927)

Ansbacher, H. L., \& Ansbacher, R. R. (Eds.). (1956). The individual psychology of Alfred Adler. New York: Basic Books.

Archer, J., Probert, B. S., \& Gage, L. (1987). College students' attitudes toward wellness. Journal of College Student Personnel, 28(4),311-317.

Baronet, A. M. (1999). Factors associated with caregiver burden in mental illness: A critical review of the research literature. Clinical Psychology Review, 19(7), 819-841.

Bedini, L., \& Phoenix, T. L. (1999). Addressing leisure barriers for caregivers of older adults: A model leisure wellness program. Therapeutic Recreation Journal, 33(3), 222-240.

Biegel, D. E., \& Schulz, R. (1999). Caregiving and caregiver interventions in aging and mental illness. Family Relations, 48, 345-354.

Cadell, S., Karabanow, J., \& Sanchez, M. (2001). Community, empowerment, and resilience: Paths to wellness. Canadian Journal of Community Mental Health, 20(1), 21-35.

Cavanaugh, J. C. (1998). Caregiving to adults: A life event challenge. In I. H. Nordhus, G. R. VandenBos, S. Berg, \& P. Fromholt (Eds.), Clinical geropsychology (pp. 131-136). Washington, DC: American Psychological Association.

Connell, C. M., Janevic, M. R., \& Gallant, M. P. (2001). The costs of caregiving: Impact of dementia on family caregivers. Journal of Geriatric Psychiatry and Neurology, 14, 179-187.

Dew, B. J. (2000). The relationship among internalized homophobia, self-disclosure, self-disclosure to parents, and wellness in adult gay males. Unpublished doctoral dissertation, University of North Carolina at Greensboro. Dunn, H. L. (1961). High-level wellness. Arlington, VA: R. W. Beatty. Dunn, H.L. (1977). What high level wellness means. Health Values: Achieving High Level Wellness, 1, 9-16.

Erdman, L. (1991). Laughter therapy for patients with cancer. Oncology Nursing Forum, 18, 1359-1363.

Erfurt, J. C., Foote, A., \& Heirich, M. A. (1991). The cost-effectiveness of work-site wellness programs for hypertension control, weight loss, and smoking cessation. Journal of Occupational Medicine, 33, 962-970. Folkman, S. (1997). Positive psychological states and coping with severe stress. Social Science and Medicine, 45(8), 1207-1221.

Gallagher-Thompson, D., Coon, D. W., Rivera, P., Powers, D., \& Zeiss, A. M. (1998). Family caregiving: Stress, coping, and intervention. In M. Hersen \& V. B. Van Hasselt (Eds.), Handbook of Clinical

Geropsychology (469-493). New York: Plenum.

Gallagher-Thompson, D., \& Powers, D. V. (1997). Primary stressors and depressive symptoms in caregivers of dementia patients. Aging and Mental Health, 2(3), 248-255.

Haley, W. E., West, C. A. C., Wadley, V. G., Ford, G. R., White, F. A., Barrett, J. J., et al. (1995).

Psychological, social, and health impact of caregiving: A comparison of Black and White dementia family caregivers and noncaregivers. Psychology and Aging, 10(4), 540-552.

Haug, M. R., Ford, A. B., Stange, K. C., Noelker, L. S., \& Gaines, A. D. (1999). Effects of giving care on caregivers' health. Research on Aging, 21(4), 515-538.

Hawkins, B. A., \& Kultgen, P. B. (1990). Activities and adaptation: A call for innovations to serve aging adults with developmental disabilities. Activities, Adaptation, and Aging, 15(1/2), 5-18.

Hermon, D., \& Hazler, R. (1999). Adherence to a wellness model and perceptions of psychological well-being. Journal of Counseling \& Development, 77, 339-343.

Hettler, W. (1984). Wellness: Encouraging a lifetime pursuit of excellence. Health Values: Achieving High Level Wellness, 8, 13-17.

Hinds, W. C. (1983). Personal paradigm shift: A lifestyle intervention approach to health care management. East Lansing, MI: Michigan State University.

Hoenig, J., \& Hamilton, M. W. (1966). The schizophrenic patient in the community and his effect on the household. The International Journal of Social Psychiatry, 12, 138-150. 
Jung, C. G. (1958). The undiscovered self (R. C. F. Hall, Trans.). New York: Mentor Books.

Knight, B. G., \& McCallum, T. J. (1998). Psychotherapy with older adult families: The contextual, cohort-based maturity/specific challenge model. In I. H. Nordhus, G. R. VandenBos, S. Berg, \& P. Fromholt (Eds), Clinical geropsychology (pp. 313-328). Washington, DC: American Psychological Association.

Kurylo, M. F., Elliott, T. R., \& Shewchuk, R. M. (2001). FOCUS on the family caregiver: A problem-solving, training intervention. Journal of Counseling \& Development, 79(3), 275-281.

Lavoie, J. P. (1995). Support groups for informal caregivers don't work! Refocus the groups of the evaluations. Canadian Journal of Aging, 14(3), 580-603.

Lewis, M., Hepburn, K., Narayan, S., Lally, R.M., Concoran-Perry, S., Maddox, M., et al. (2000). Decision making by family caregivers of elders experiencing dementia. American Journal of Alzheimer's Disease, 15(6), 361-366.

Light, E., Niederehe, G., \& Lebowitz, B. D. (1994). Stress effects on family caregivers of Alzheimer's patients: Research and interventions. New York: Springer.

Logsdon, M. C., \& Robinson, K. (2000). Helping women caregivers obtain support: Barriers and recommendations. Archives of Psychiatric Nursing, 14(5), 244-248.

Maslow, A. (1970). Motivation and personality (2nd ed.). New York: Harper \& Row. (Original work published 1954)

Matthews, J. T. (1998). Adherence to preventive health practices among family caregivers of persons receiving home health services. Dissertation Abstracts International, Section B, the Sciences and Engineering, 59(6B),

2683.

McNally, S., Ben-Shlomo, Y., \& Newman S. (1999). The effects of respite care on informal carers' well being: A systematic review. Disability and Rehabilitation, 21(1), 1-14.

Muscroft, J., \& Bowl, R. (2000). The impact of depression on caregivers and other family members:

Implications for professional support. Counselling Psychology Quarterly, 13(1), 117-134.

Myers, J. E., Madathil, J., \& Tingle, L. R. (in press). Marriage satisfaction and wellness in India and the United States: A preliminary comparison of arranged marriage and marriages of choice. Journal of Counseling \& Development.

Myers, J. E., Sweeney, T. J., \& Witmer, J. M. (1998). The wellness evaluation of lifestyle. Palo Alto, CA: MindGarden.

Myers, J. E., Sweeney, T. J., \& Witmer, M. (2000). The wheel of wellness, counseling for wellness: A holistic model for treatment planning. Journal of Counseling and Development, 78, 251-266.

Myers, J. E., Sweeney, T. J., \& Witmer, J. M. (2001) The wellness evaluation of lifestyle. Palo Alto, CA: MindGarden.

National Alliance for Caregiving and the American Association of Retired Persons. (1997). Family Caregiving in the U.S.: Findings from a National Survey. Bethesda, MD: Author.

Pearlin, L. I. (1994). Conceptual strategies for the study of caregiver stress. In E. Light, G. Niederehe, \& B. D. Lebowitz, (Eds.), Stress effects on family caregivers of Alzheimer's patients: Research and interventions (pp. 324). New York: Springer.

Pearlin, L. I., Mullan, J. T., Semple, S., \& Skaff, M. M. (1990). Caregiving and the stress process: An overview of concepts and their measures. The Gerontologist, 30(5), 583-594.

Prochaska, J. O., Norcross, J. C., \& DiClemente, C. C. (1994). Changing for good: A revolutionary six-stage program for overcoming bad habits and moving your life positively forward. New York: Avon Books.

Rabins, P. V. (1998). The caregiver's role in Alzheimer's disease. Dementia and Geriatric Cognitive Disorders, 9(3), 25-28.

Ragheb, M. G. (1993). Leisure and perceived wellness: A field investigation. Leisure Sciences, 15, 13-24.

Reitzes, D. C., Mutra, E. J., \& Verrill, L. A. (1995). Activities and self-esteem: Continuing the development of activity theory. Research on Aging, 17, 260-277.

Roberts, J., Browne, G., Gafni, A., Varieur, M., Loney, P., \& de Ruijter, M. (2000). Specialized continuing care models for persons with dementia: A systematic review of the research literature. Canadian Journal on Aging, 19(1), 106-126.

Roberts, M., \& Harris, T. G. (1989). Wellness at work. Psychology Today, 23, 54-58. 
Rogers, N. B. (1999). Caring for those who care: Achieving family caregiver wellness through social support programs. Activities, Adaptation, and Aging, 24(1), 1-12.

Schultz, R., \& Beach, S. R. (1999). Caregiving as a risk factor for mortality: The caregiver health effects study. Journal of the American Medical Association, 282, 2215-2219.

Schulz, R., Newsom, J. T., Fleissner, K., DeCamp, A. R., \& Nieboer, A. P. (1997). The effects of bereavement after family caregiving. Aging and Mental Health, 1(3), 269-282.

Schulz, R., \& Salthouse (1999). Adult development and aging: Myths and emerging realities. Upper Saddle River, NJ: Prentice Hall.

Schulz, R., \& Williamson, G. M. (1994). Health effects of caregiving: Prevalence of mental and physical illness in Alzheimer's caregivers. In E. Light, G. Niederehe, \& B. D. Lebowitz (Eds.), Stress effects on family caregivers of Alzheimer's patients: Research and interventions (pp. 38- 63). New York: Springer.

Schwiebert, V. L., \& Myers, J. E. (1994). Midlife care givers: Effectiveness of a psychoeducational intervention for midlife adults with parent-care responsibilities. Journal of Counseling and Development, 72(6), 627 - 637. Sweeney, T. J., \& Witmer, J. M. (1991). Beyond social interest: Striving toward optimal health and wellness. Individual Psychology, 47,527-540.

Tennstedt, S. (1999, March). Family caregiving in an aging society. Paper presented at the U.S. Administration on Aging Symposium: Longevity in the New American Century, Baltimore, MD. Retrieved from http:// www.aoa.dhhs.gov/caregivers/FamCare.html

Vitalioano, P. P., Schulz, R., Kiecolt-Glaser, J., \& Grant, I. (1997). Research on physiological and physical concomitants of caregiving: Where do we go from here? Annals of Behavioral Medicine, 19(2), 117-123.

Vrabec, N. J. (1997). Literature review of social support and caregiver bur-

den, 1980-1995. Journal of Nursing Scholarship, 29(4), 383-388.

Waters, E. (1995). Let's not wait till it's broke: Interventions to maintain and enhance mental health in later life. In M. Gatz (Ed.), Emerging issues in mental health and aging (pp. 183-209). Washington, DC: American Psychological Association.

Witmer, J. M. (1996). Reaching toward wellness: A holistic model for personal growth and counseling. Athens, $\mathrm{OH}$ : Author.

Witmer, J. M., \& Sweeney, T. J. (1992). A holistic model for wellness and prevention over the lifespan. Journal of Counseling and Development, 71, 140-148.

World Health Organization. (1958). Constitution of the World Health Organization (Annex). Geneva, Switzerland: Author.

World Health Organization. (1964). Basic documents (15th ed.). Geneva, Switzerland: Author.

Yee, J. L., \& Schulz, R. (2000). Gender differences in psychiatric morbidity among family caregivers: A review and analysis. The Gerontologist, 40(2), 147-164.

Zarit, S. H., Birkel, R. C., \& Malone-Beach, E. (1989). Spouses as caregivers: Stresses and interventions. In M. Z. Goldstein (Ed.), Family involvement in the treatment of the frail elderly. Washington, DC: American Psychiatric Association.

Zarit, S. H., Johansson, L., \& Jarrott, S. E. (1998). Family caregiving: Stresses, social programs, and clinical interventions. In I. H. Nordhus, G. R. VandenBos, S. Berg, \& P. Fromholt (Eds). Clinical geropsychology (pp. 345-360). Washington, DC: American Psychological Association.

Zimmer, Z., \& Lin, H. S. (1996). Leisure activity and well-being among the elderly in Taiwan: Testing hypotheses in an Asian setting. Journal of Cross-Cultural Gerontology, 11, 167-186. 